\title{
Primary research
}

\section{Hyperbilirubinaemia after major thoracic surgery: comparison between open-heart surgery and oesophagectomy Kikumi K Hosotsubo, Masaji Nishimura and Shinya Nishimura

\author{
Osaka University Hospital, Suita, Japan
}

Received: 4 November 1999

Revisions requested: 7 January 2000

Revisions received: 6 February 2000

Accepted: 21 February 2000

Published: 27 March 2000
Crit Care 2000, 4:180-187

(c) Current Science Ltd

\begin{abstract}
Background: Hyperbilirubinaemia is a common occurrence in patients who are admitted to intensive care units (ICUs) after major surgery, and it is associated with high mortality. We investigated the incidence of hyperbilirubinaemia after two major types of thoracic surgery: open-heart surgery and oesophagectomy. In order to identify the risk factors associated with hyperbilirubinaemia after major surgery, we compared the incidence after open-heart surgery with that after oesophagectomy.
\end{abstract}

Results: Hyperbilirubinaemia was detected in $51 \%$ of the open-heart surgery patients $(n=133)$ and in $64 \%$ in the oesophagectomy group $(n=74)$. The incidence of hyperbilirubinaemia was significantly related to the duration of surgery $(P<0.05)$. In the open-heart surgery group, duration of surgery was $465 \pm 24$ min for the patients without hyperbilirubinaemia and $571 \pm 26 \mathrm{~min}$ for the patients with hyperbilirubinaemia. In the oesophagectomy group, the procedure durations were $415 \pm 17 \mathrm{~min}$ and $493 \pm 20 \mathrm{~min}$, respectively. The overall mortality rate was $8 \%$ in the open-heart surgery group; the rate was $12 \%$ in those with hyperbilirubinaemia, but $5 \%$ in those without hyperbilirubinaemia. No members of the oesophagectomy group died, with or without hyperbilirubinaemia. Infection significantly affected both the occurrence of hyperbilirubinaemia and mortality in the openheart surgery group. In the subgroups from the open-heart surgery group, 5\% (three out of 65 ) of those without hyperbilirubinaemia (or evidence of infection) died; of the patients with hyperbilirubinaemia, 3\% (one out of 38) of those without infection died and 23\% (seven out of 30) with detected infection died.

Conclusion: After open-heart surgery and oesophagectomy, approximately half of the patients studied had higher levels of serum total bilirubin. Time spent in surgery was significantly related to the occurrence of hyperbilirubinaemia. Infection significantly affected mortality and total bilirubin levels after open-heart surgery. Control of infection plays a crucial role in the prevention of hyperbilirubinaemia and in reducing mortality.

Keywords: hepatic function, hyperbilirubinaemia, oesophagectomy, open-heart surgery

$\mathrm{CPB}=$ cardiopulmonary bypass; $\mathrm{CRP}=\mathrm{C}$-reactive protein; $\mathrm{ICU}=$ intensive care unit $\mathrm{POD}=$ postoperative day; $\mathrm{TB}=$ total bilirubin; $\mathrm{WBC}=$ white blood cell. 


\section{Introduction}

Researchers have reported rates of hyperbilirubinaemia after cardiac operations involving cardiopulmonary bypass (CPB) that range from approximately $5 \%$ [1] to $20 \%$ or even as high as 40\% [2]. Hypoperfusion, haemodilution and other factors that reduce the delivery of oxygen to the liver or increase the bilirubin load are thought to cause postoperative hyperbilirubinaemia. Most reports, however, have been on patients who have undergone open-heart surgery, and the effect of CPB may be a contributory factor. It has not been determined whether CPB itself, thoracotomy, or surgical invasion of the body increases the incidence of postoperative hyperbilirubinaemia. There is little data from which to judge whether CPB itself is a major factor, or whether other factors induce hyperbilirubinaemia. On the other hand, oesophagectomy is one of the most invasive thoracic surgeries, and hyperbilirubinaemia is detected more frequently after oesophagectomy than after other operations $[3,4]$.

Hyperbilirubinaemia also frequently accompanies sepsis, which is correlated with mortality $[5,6]$. Infection is the most common complication after surgery, and it is therefore possible that, in addition to operative factors, postoperative infection may also contribute to the development of hyperbilirubinaemia after major surgery. The effect of postoperative infection on the development of hyperbilirubinaemia has not yet been systematically investigated, however. In the present study, we compared the incidence of hyperbilirubinaemia in patients after cardiac surgery and oesophagectomy in order to evaluate whether CPB was related to postoperative hyperbilirubinaemia. In addition, we investigated the extent to which the presence of infection was related to the development of hyperbilirubinaemia. Patients who develop hyperbilirubinaemia require longer stays in the ICU, which frustrates attempts to expedite the recovery of patients [7]. In order to prevent its development, it is important to know the risk factors for hyperbilirubinaemia.

The purpose of the present study was to examine the incidence and nature of postoperative hyperbilirubinaemia in patients undergoing different kinds of thoracic operations, to identify the perioperative and surgical risk factors associated with postoperative hyperbilirubinaemia, and to determine how postoperative hyperbilirubinaemia is related to mortality and morbidity.

\section{Patients and methods}

We retrospectively investigated 207 adult patients (all older than 18 years) who had been admitted to our ICU during the 2-year period from March 1996 to February 1998 following a major operative procedure. Of the patients studied, 133 had undergone open-heart surgery (C group) and 74 had undergone oesophagectomy (E group). We chose these two types of surgery because both are highly invasive of the thorax. The operations of all of the $\mathrm{C}$ group patients involved CPB, so comparing data from these patients with those from patients subjected to similarly invasive surgery without CPB may shed some light on the effect of CPB on postoperative hyperbilirubinaemia. Most of the patients in the $C$ group were anaesthetized with narcotics. In the $\mathrm{C}$ group, 51 patients had coronary artery disease, 64 valvular diseases and 18 had a thoracic aortic aneurysm. All of the patients in the Egroup had oesophageal cancer. They were anaesthetized with isoflurane or propofol. No patients in either group showed any preoperative clinical signs of bacterial infection except for a single patient in the $\mathrm{C}$ group.

Preoperative venous blood samples were subjected to biochemical analysis for hepatobiliary function and identification of hepatitis viruses. After the operation, blood was drawn from arterial lines for biochemical analysis. Blood samples were analyzed for concentrations of total bilirubin (TB), conjugated bilirubin, unconjugated bilirubin, alanine aminotransferase, asparate aminotransferase, lactate dehydrogenase and alkaline phosphatase. Blood samples were obtained on postoperative days (PODs) 1, 2, 3, 5, 7, 9, 11 and 14. Postoperative hyperbilirubinaemia was defined as TB concentrations over $2 \mathrm{mg} / \mathrm{dl}$ within 14 days after the operation.

To provide evidence of infection, blood samples were also analyzed for C-reactive protein (CRP) and white blood cells (WBCs). When infection was suspected, samples were tested for circulating endotoxin, $\beta$-glucan and Candida protein antigens. Patients were routinely monitored for infection using clinical judgement and data for CRP and WBCs. Perioperative infection was considered present when at least one of following three conditions was fulfilled: WBC greater than $12000 / \mu \mathrm{l}$ and body temperature greater than $38^{\circ} \mathrm{C}$ or less than $36^{\circ} \mathrm{C}$; the same species of bacteria was detected from two different sites; and endotoxin greater than $5 \mathrm{pg} / \mathrm{ml}$ and $\beta$-glucan greater than $50 \mathrm{pg} / \mathrm{ml}$, or positive Candida protein antigens. Biochemical analysis (TB, conjugated bilirubin, unconjugated bilirubin, CRP and liver enzymes) was performed using an automated analyzer (COBAS MIRA Plus; Japan Roche, Tokyo, Japan). Hepatitis viruses were detected using immunoassay (hepatitis B virus - Counting Immunoassay Sysmex Runream, Toa Medical Electron, Kobe, Japan; hepatitis C virus - ELISA Test III, Ortho-Clinical Diagnostics, Tokyo, Japan). Endotoxin and $\beta$-glucan were measured using commercially available chromogenic assays (Endospecy ES and Toxicolor System LS; Seikagaku Industries Corporation, Tokyo, Japan). A Candida detection system that employs latex agglutination (Ramco Laboratories, Houston, TX, USA) was used to test for Candida protein antigens. In order to identify the presence of fungal infection, $\beta$-glucan and Candida protein antigens were measured. The results of these tests were collated by reviewing the ICU laboratory data sheets. 
The surgical factors investigated, by reviewing anesthesia records, were operative time and volume of blood transfused. All patients were tracked for at least 1 month after the operation to evaluate postoperative mortality.

\section{Statistical analysis}

Data are expressed as mean \pm standard error of the mean. Multiple comparisons were performed using analysis of varience. Patients' characteristics were compared using Scheffe's test for continuous variables (preoperative liver enzymes, TB, conjugated bilirubin, operative time and volume of blood transfused). In the subgroups of the patients with hyperbilirubinaemia and without hyperbilirubinaemia, Scheffe's test was used for continuous variables (TB, CRP, WBCs) on each POD. Duration of stay in ICU was compared using Wilcoxon's test. For categorical variables (sex, existence of hyperbilirubinaemia, bacterial infection, type of surgical procedure), $\chi^{2}$ analyses were performed. Fisher's test was used to compare the mortality between the $\mathrm{C}$ and the $\mathrm{E}$ groups. $P<0.05$ was considered statistically significant.

\section{Results}

Table 1 shows the demographic characteristics of the patients, along with preoperative data for biochemistry of hepatobiliary function, presence of hepatitis viruses, operative time and volume of blood transfused for each group of patients. Except for the male:female ratio, the baseline characteristics of the 207 patients in the study were similar for both groups. The higher proportion of male patients in the oesophagectomy group (E group) reflects the generally higher occurrence of oesophageal cancer in males. In the open-heart surgery group (C group), 13 patients were positive for hepatitis $\mathrm{C}$ virus and two had hyperbilirubinaemia. In the E group, seven patients were positive for hepatitis $\mathrm{C}$ virus and none had hyperbilirubinaemia. Only one patient was a carrier of hepatitis B virus in the $\mathrm{C}$ group, and this patient did not show liver dysfunction either before or after the operation. The mean age was similar in the both groups. The liver function tests of all patients were within the normal range, and the value for serum bilirubin and duration of operation did not differ significantly between the groups. Patients in the $\mathrm{C}$ group received larger volumes of transfused blood during surgery than did those in the E group (Table 2).

\section{Incidence and nature of hyperbilirubinaemia}

Postoperative hyperbilirubinaemia was detected in 56\% (115 out of 207) of the patients in the two groups combined. It was present in $51 \%$ of the $C$ group patients and in $64 \%$ of the $E$ group patients. The incidence of hyperbilirubinaemia did not differ significantly between the groups, and it did not vary according to the procedures used in the $\mathrm{C}$ group (Table 3 ). In patients without hyperbilirubinaemia, TB levels peaked on POD $1(1.3 \pm 0.09 \mathrm{mg} / \mathrm{dl}$ in the $\mathrm{C}$ group, and $1.2 \pm 0.06 \mathrm{mg} / \mathrm{dl}$ in the $\mathrm{E}$ group), and
Table 1

\begin{tabular}{lcc} 
Preoperative characteristics & & \\
\hline & C group & E group \\
\hline$n$ & 133 & 74 \\
Sex (male/female) & $78 / 55^{\star}$ & $56 / 18$ \\
Age (years) & $60.0 \pm 1.3$ & $58.9 \pm 1.3$ \\
Hyperbilirubinaemia & 2 & 0 \\
Hepatitis C virus positive & 13 & 7 \\
Bacterial infection & 1 & 0 \\
Total bilirubin (mg/dl) & $0.8 \pm 0.06$ & $0.7 \pm 0.05$ \\
Conjugated bilirubin (mg/dl) & $0.2 \pm 0.02$ & $0.2 \pm 0.01$ \\
Alanine aminotransferase (IU/I) & $18 \pm 1.9$ & $19 \pm 2.7$ \\
Aspartate aminotransferase (IU/I) & $19 \pm 1.9$ & $23 \pm 1.8$ \\
Lactate dehydrogenase (IU/l) & $321 \pm 28.8$ & $246 \pm 15.0$ \\
Alkaline phophatase (IU/I) & $122 \pm 7.2$ & $118 \pm 6.0$ \\
CRP (mg/dl) & $0.5 \pm 0.36$ & $0.6 \pm 0.39$ \\
WBC count (cells/mm ${ }^{3}$ ) & $6532 \pm 574$ & $5799 \pm 366$ \\
\hline Patients ingroup C were & & \\
\hline
\end{tabular}

Patients in group $\mathrm{C}$ were subjected to open-heart surgery; patients in group $E$ were subjected to oesophagectomy. Data are expressed as mean \pm standard error. ${ }^{*} P<0.05$, versus group $E$ patients.

then decreased gradually to preoperative values by POD 7. In patients with hyperbilirubinaemia, TB levels remained above the normal range even by POD 14. In patients with hyperbilirubinaemia in the $\mathrm{C}$ group, TB levels increased toward peak values on POD 11; in patients with hyperbilirubinaemia in the E group, TB levels peaked on POD 5 and then gradually decreased (Fig. 1).

\section{Incidence of postoperative infection and hyperbilirubinaemia}

CRP values increased significantly on POD 1 , peaked on POD 2 or 3 , and then decreased gradually. WBC values also increased significantly after surgery. In the E group WBC values showed a biphasic pattern, the first peak occurring on POD 2 and the second on PODs 9-11. In the $C$ group 24\% (32 out of 133) and in the $E$ group 55\% (41 out of 74 ) of patients met the criteria for infection. These infected patients showed significantly increased incidence of hyperbilirubinaemia: 94\% (30 out of 32) of patients in the $\mathrm{C}$ group and 85\% (35 out of 41 ) of patients in the Egroup. Postoperative infection correlated with serum TB levels in patients with hyperbilirubinaemia. In the $C$ group, TB values in patients without infection peaked on POD $3(2.9 \pm 0.37 \mathrm{mg} / \mathrm{dl})$ and then decreased. In the E group, TB values for infected patients exhibited a biphasic pattern; after a postoperative increase, TB levels decreased before rising to hit peak values $(3.0 \pm 0.35 \mathrm{mg} / \mathrm{dl})$ on POD 5 (Fig. 2). 
Table 2

\begin{tabular}{|c|c|c|}
\hline & C group & E group \\
\hline Operative time (min) & $517 \pm 25$ & $464 \pm 19$ \\
\hline Transfused volume of blood (ml) & $2711 \pm 353^{*}$ & $663 \pm 154$ \\
\hline Total bilirubin (mg/dl) & $3.3 \pm 0.68$ & $3.0 \pm 0.26$ \\
\hline Conjugated bilirubin (mg/dl) & $1.4 \pm 0.35$ & $1.1 \pm 0.13$ \\
\hline Alanine aminotransferase (IU/I) & $19 \pm 2.2$ & $19 \pm 2.6$ \\
\hline Aspartate aminotransferase (IU/I) & $23 \pm 2.2$ & $23 \pm 2.1$ \\
\hline Lactate dehydrogenase (IU/I) & $340 \pm 34.6$ & $249 \pm 17.8$ \\
\hline Alkaline phosphatase (IU/I) & $128 \pm 7.8$ & $120 \pm 5.7$ \\
\hline CRP (mg/dl) & $17.5 \pm 1.14$ & $21.7 \pm 1.32$ \\
\hline WBC count (cells/mm³) & $11369 \pm 597$ & $10958 \pm 654$ \\
\hline $\begin{array}{l}\text { Number of patients with hypotensio } \\
\text { (SBP }<80 \mathrm{mmHg} \text { ) }\end{array}$ & ion & 8 \\
\hline $\begin{array}{l}\text { Hypoxia (arterial oxygen tension } \\
<60 \mathrm{mmHg} \text { ) }\end{array}$ & 0 & 0 \\
\hline CRP (mg/dl) & $0.5 \pm 0.36$ & $0.6 \pm 0.39$ \\
\hline Use of vasopressors & 127 & 58 \\
\hline \multicolumn{3}{|l|}{ Isolated organisms } \\
\hline Gram-positive bacteria & 19 & 12 \\
\hline Gram-negative bacteria & $24^{*}$ & 31 \\
\hline Fungi & $11^{*}$ & 1 \\
\hline \multicolumn{3}{|l|}{ Biochemical tests } \\
\hline Endotoxin $(>5 \mathrm{pg} / \mathrm{ml})$ & 28 & 32 \\
\hline$\beta$-glucan $(>50 \mathrm{pg} / \mathrm{ml})$ & $10^{*}$ & 1 \\
\hline Antibiotics & $94^{*}$ & 71 \\
\hline Antifungal agents & 10 & 1 \\
\hline Tube feeding & $6^{*}$ & 36 \\
\hline
\end{tabular}

Patients in group $\mathrm{C}$ were subjected to open-heart surgery; patients in group E were subjected to oesophagectomy. Data are expressed as mean \pm standard error. The maximum values of TB, conjugated bilirubin, alanine aminotransferase, aspartate amintransferase, lactate dehydrogenase, alkaline phosphatase, CRP and WBC after operation are shown. ${ }^{\star} P<0.05$ versus patients in group E. SBP, systolic blood pressure.

For patients who had both hyperbilirubinaemia and postoperative infection in $\mathrm{C}$ and $\mathrm{E}$ groups, peaks of TB value were $8.5 \pm 2.49 \mathrm{mg} / \mathrm{dl}$ in the $\mathrm{C}$ group and $3.4 \pm 0.23 \mathrm{mg} / \mathrm{dl}$ in the Egroup, which occurred on PODs 11 and 5 , respectively. In both groups, postoperative infection correlated closely with the development of hyperbilirubinaemia.

\section{Risk factors for hyperbilirubinaemia}

Table 4 shows the factors that were considered to be related to the development of hyperbilirubinaemia. In both groups, patients with hyperbilirubinaemia were in surgery
Table 3

\begin{tabular}{lcc}
$\begin{array}{l}\text { Incidence of hyperbilirubinaemia according to surgical } \\
\text { procedure }\end{array}$ & $n$ & $\begin{array}{c}\text { Patients with } \\
\text { hyperbilirubinaemia (\%) }\end{array}$ \\
\hline Cardiac surgery & 133 & $68(51)$ \\
Coronary artery bypass grafting & 51 & $22(43)$ \\
Valvular procedures & 64 & $37(58)$ \\
Aneurysm & 18 & $9(50)$ \\
Oesophagectomy & 74 & $47(64)$ \\
\hline
\end{tabular}

No significant differences in the incidence of hyperbilirubinaemia were observed between the surgical procedures.

for significantly longer than those without. In the C group, preoperative concentration of serum bilirubin also correlated with postoperative hyperbilirubinaemia. Liver enzyme data did not differ significantly between the patients with and without hyperbilirubinaemia.

\section{Mortality and morbidity}

The overall mortality rate was $8 \%$ in the $\mathrm{C}$ group; mortality was $12 \%$ in those with hyperbilirubinaemia and $5 \%$ in those without it. None of the E group patients died, with or without hyperbilirubinaemia. Infection significantly correlated with both the occurrence of hyperbilirubinaemia and mortality in the $\mathrm{C}$ group. In the subgroups of patients from group C, 5\% (three out of 65) of those without hyperbilirubinaemia (or evidence of infection) died; in the patients with hyperbilirubinaemia, 3\% (one out of 38 ) of those without infection died and 23\% (seven out of 30) with detected infection died (Table 5). In both groups, patients without hyperbilirubinaemia left the ICU sooner than those with hyperbilirubinaemia (Table 6).

\section{Discussion}

The present study found that hyperbilirubinaemia developed in 56\% of patients in the ICU who had undergone open-heart surgery or oesophagectomy; that infection during the perioperative period correlated with the development of hyperbilirubinaemia; that other risk factors for hyperbilirubinaemia were operative time and volume of blood transfused during surgery; and that in the openheart surgery group (C group) mortality was significantly higher for patients with hyperbilirubinaemia than for those without it.

The study presents for the first time comparative results regarding the development of postoperative hyperbilirubinaemia after two types of major thoracic operation. Other authors have reported the incidence of hyperbilirubinaemia after heart operations with CPB or have investigated the risk factors for hyperbilirubinaemia after cardiac surgery $[1,2,8]$. Here, we compare the incidence of hyper- 
(a)

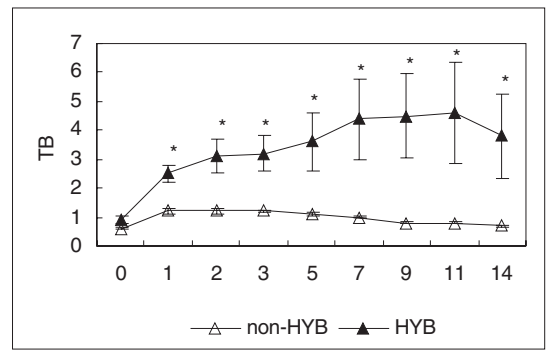

(b)

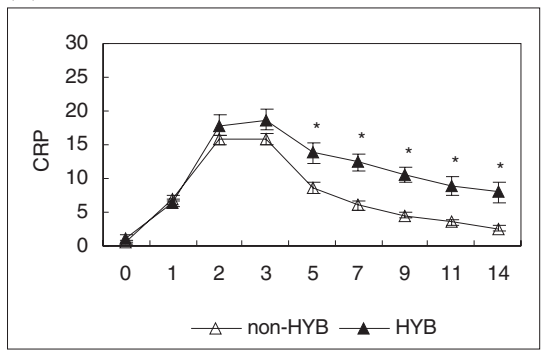

(c)

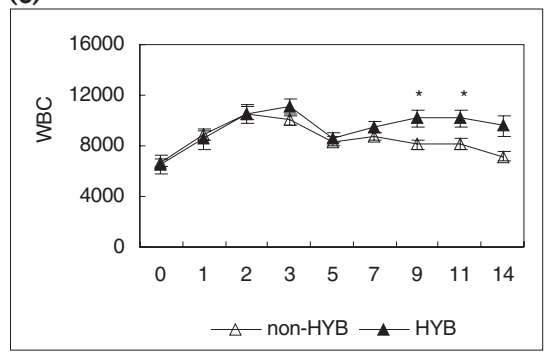

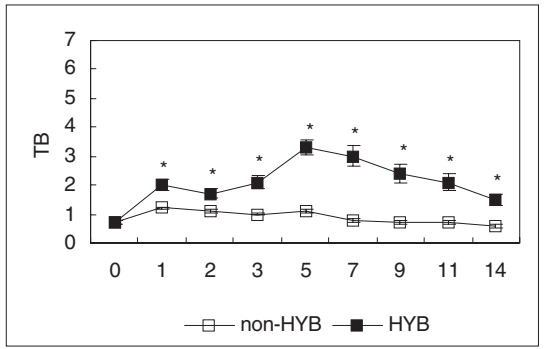
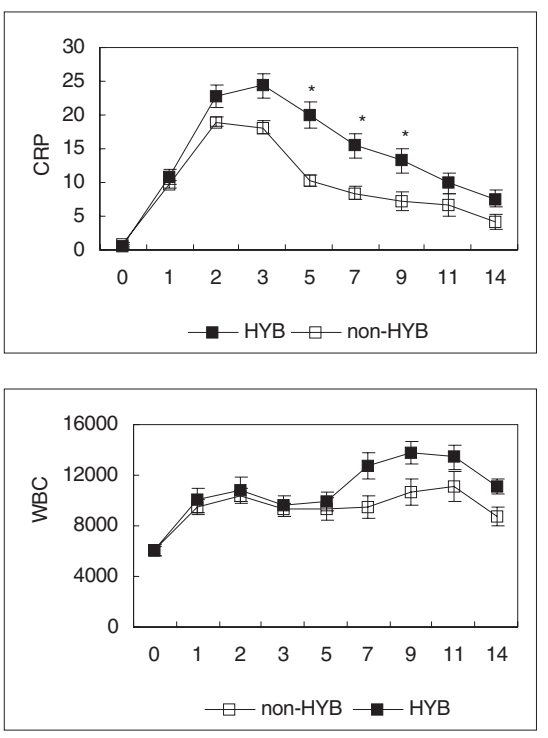

(a) Course of TB, (b) CRP and (c) WBC in each group [left column, $\mathrm{C}$ group (open-heart surgery); right column, E group (oesophagectomy)] after operation. Open trianges show each parameter in the $\mathrm{C}$ group patients without hyperbilirubinaemia (HYB), and closed trigangles show each parameter in the $\mathrm{C}$ group patients with hyperbilirubinaemia. Open squares show each parameter in the $E$ group patients without hyperbilirubinaemia, and closed squares show each parameter in the $E$ group patients with hyperbilirubinaemia. ${ }^{*} P<0.05$, versus $\mathrm{HYB}$. bilirubinaemia after open-heart surgery and oesophagectomy. This comparison is helpful in evaluating the cooccurrence of CPB with hyperbilirubinaemia after surgery.

The incidence of hyperbilirubinaemia in the patients studied was generally higher than the rates reported by other authors. Wang et al [2] pointed out that, despite a decade of advance in CPB and anaesthesia techniques, the incidence of hyperbilirubinaemia after cardiac operations with CPB did not decrease. Various reasons have been advanced to explain the development of postoperative hyperbilirubinaemia. The present study clearly shows that the longer the operative time and the larger the volume of blood transfused, the higher the incidence of postoperative hyperbilirubinaemia. The patients in this study spent longer times in the operation room than those in other reports; this may be one of the reasons why the incidence of hyperbilirubinaemia was comparatively high.

The incidence of hyperbilirubinaemia did not differ significantly between the $\mathrm{C}$ and $\mathrm{E}$ groups, and neither did operative time. If CPB per se is connected to the development of hyperbilirubinaemia, the incidence of hyperbilirubinaemia would have been higher in the $C$ than in the
E group. The present results show no difference between the groups, however, which would suggest that CPB is not a major factor in the postoperative development of hyperbilirubinaemia.

We also evaluated the effect of bacterial infection on the development of hyperbilirubinaemia. Bacterial infection is a known cause of hepatic dysfunction, and hyperbilirubinaemia often occurs with sepsis. After major surgery, bacterial infection is a common complication that probably increases the risk of hyperbilirubinaemia. Clinically, it is difficult to diagnose every case of postoperative bacterial infection reliably. For the purpose of the present study, which used retrospective data, we arbitrarily defined infection using broad criteria for assessing infection in the critically ill.

Wang et al [2] reported significantly higher mortality in patients with postoperative hyperbilirubinaemia whose TB levels peaked on POD 7 than in hyperbilirubinaemic patients whose TB levels peaked on POD 1 or 2 [2]. They did not present any explanation for why TB increased late after operation. The present results suggest a possible answer, however. In the patient sample studied, those with bacterial infection showed peak TB levels on POD 11 in the 
(a)

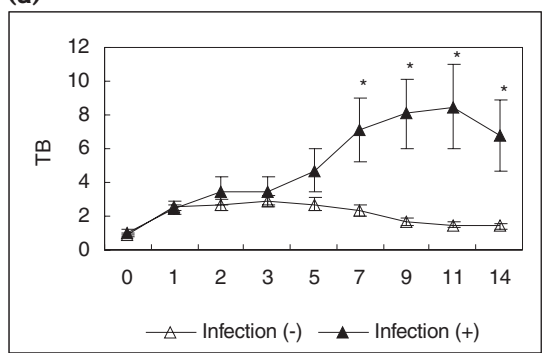

(b)

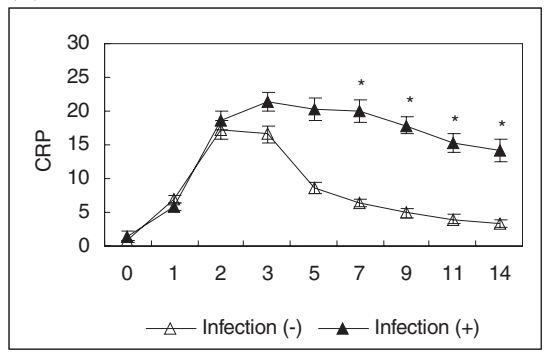

(c)

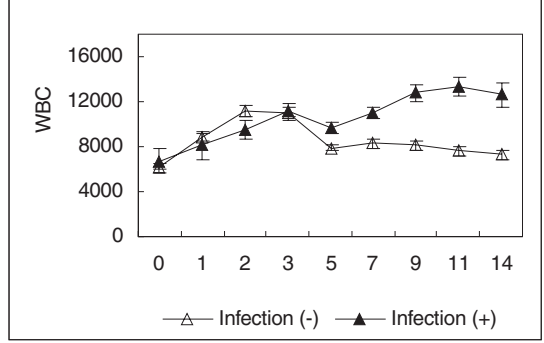

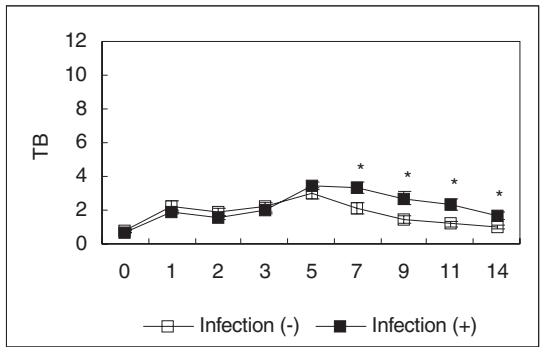
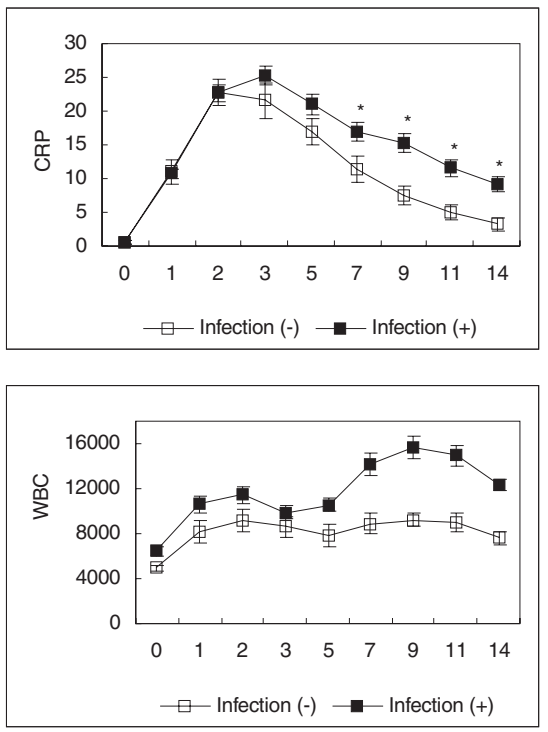

Patients with hyperbilirubinaemia were divided into two subgroups according to the existence of infection. (a) Course of TB, (b) CRP and (c) WBC in subgroups of each group [left column, $\mathrm{C}$ group (open-heart surgery); right column, E group (oesophagectomy)] after operation. Open triangles show each parameter in the $\mathrm{C}$ group patients without infection, and closed triangles show each parameter in the $\mathrm{C}$ group patients with infection. Open squares show each parameter in the $E$ group patients without infection, and closed squares show each parameter in the $E$ group patients with infection. ${ }^{\star} P<0.05$, versus infection.
C group and POD 5 in the E group; in addition, peak levels were generally higher in patients classified as infected.

The majority of patients showed TB levels of greater than $2 \mathrm{mg} / \mathrm{dl}$, and rates found in the present report were higher than those reported elsewhere. Depending on the report, the incidence of hyperbilirubinaemia varies greatly, from as low as $3 \%$ to as high as $40 \%$. These reports generally cover a single week of postoperative observation. Following the example of Ryan et al [7], we analyzed data from a 2-week period. Wang et al [2] also reported that hyperbilirubinaemia developed a couple of days after the operation, but it did not increase mortality, whereas the late increase in TB was related to high mortality. Although the long observation time was one of the reasons for high incidence of hyperbilirubinaemia found in the present study, the incidence did not change if we limited the observation time from 2 weeks to 1 week. Consequently, the longer period of observation could not explain the high rate of hyperbilirubinaemia found in the present study. Operative time is an important factor that correlates with postoperative hyperbilirubinaemia, and the periods in the present study were long. This may explain the high incidence of hyperbilirubinaemia. The operative time in the report of
Wang et al [2] was $269 \pm 6$ min, which is a shorter operative period than for either the $C(517 \pm 25 \mathrm{~min})$ or the $E$ (464 $\pm 19 \mathrm{~min})$ group studied in the present study.

Wang et al [2] also reported mortality of 5.6\% for patients with postoperative hyperbilirubinaemia, whereas Collins et al [8] reported a $25 \%$ mortality for similar patients. The present sample shows a total mortality of $4.8 \%$, with the only fatalities occurring in the $\mathrm{C}$ group, in which $7.5 \%$ of the patients died. The mortality of the patients with postoperative hyperbilirubinaemia was $7.0 \%$ (C group, 12\%; Egroup, 0\%). The association of postoperative hyperbilirubinaemia with higher postoperative morbidity and mortality was noted. Our finding that high mortality is more likely in patients who show delayed postoperative peak hyperbilirubinaemia is comparable to the findings of Wang et al [2]. The results of the present study suggest that postoperative infection correlates with hyperbilirubinaemia in the later postoperative period.

Collins et al [8] and Chu et al [9] reported that jaundice after CPB was mainly a symptom of conjugated hyperbilirubinaemia, and have suggested that this is due to failure to excrete bilirubin. In contrast, a report by Klepetko 


\begin{tabular}{|c|c|c|c|c|}
\hline & \multicolumn{2}{|c|}{ C group } & \multicolumn{2}{|c|}{ E group } \\
\hline & $\begin{array}{c}\text { non-HYB } \\
(n=65)\end{array}$ & $\begin{array}{c}\text { HYB } \\
(n=68)\end{array}$ & $\begin{array}{c}\text { Non-HYB } \\
(n=27)\end{array}$ & $\begin{array}{c}\text { HYB } \\
(n=47)\end{array}$ \\
\hline Age (years) & $58 \pm 1.4$ & $62 \pm 1.3$ & $57 \pm 1.7$ & $60 \pm 1.1$ \\
\hline Sex (male/female) & $39 / 26$ & $39 / 29$ & $17 / 10$ & $39 / 8$ \\
\hline Operative time (min) & $465 \pm 24$ & $571 \pm 26^{*}$ & $415 \pm 17$ & $493 \pm 20^{*}$ \\
\hline Transfusion (ml) & $2000 \pm 260$ & $3426 \pm 441^{*}$ & $277 \pm 73$ & $890 \pm 201$ \\
\hline Preoperative TB (mg/dl) & $0.6 \pm 0.03$ & $0.9 \pm 0.09^{*}$ & $0.7 \pm 0.06$ & $0.7 \pm 0.04$ \\
\hline Preoperative conjugated bilirubin (mg/dl) & $0.2 \pm 0.01$ & $0.3 \pm 0.03^{*}$ & $0.2 \pm 0.02$ & $0.2 \pm 0.01$ \\
\hline Preoperative alanine aminotransferase (IU/I) & $18 \pm 1.3$ & $19 \pm 2.5$ & $15 \pm 2.1$ & $22 \pm 3.1$ \\
\hline Preoperative aspartate aminotransferase (IU/I) & $16 \pm 0.8$ & $22 \pm 2.9$ & $16 \pm 1.7$ & $20 \pm 1.9$ \\
\hline Preoperative lactate dehydrogenase (IU/I) & $274 \pm 11.2$ & $367 \pm 45.6$ & $231 \pm 11.6$ & $255 \pm 17.0$ \\
\hline Preoperative alkaline phosphatase (IU/I) & $117 \pm 5.5$ & $128 \pm 8.9$ & $113 \pm 7.1$ & $121 \pm 5.3$ \\
\hline Hepatatis $\mathrm{C}$ virus positive & 3 & 10 & 2 & 5 \\
\hline Preoperative HYP & 0 & 2 & 0 & 0 \\
\hline
\end{tabular}

Patients in group $\mathrm{C}$ were subjected to open-heart surgery; patients in group $\mathrm{E}$ were subjected to oesophagectomy. Data are expressed as mean \pm standard error. ${ }^{*} P<0.05$, versus patients without hyperbilirubinaemia (HYB).

Table 5

Effect of infection on the incidence of postoperative hyperbilirubinaemia

\begin{tabular}{lccccc}
\hline & \multicolumn{2}{c}{ C group } & & \multicolumn{2}{c}{ E group } \\
\cline { 2 - 3 } \cline { 5 - 6 } \cline { 5 - 6 } & Noninfected & Infected & & Noninfected & Infected \\
\hline$n$ & 101 & 32 & & 33 & 41 \\
non-HYB & $63(62)$ & $2(6)$ & & $21(64)$ & $6(15)$ \\
Mortality & $3(3)$ & $0(0)$ & & $0(0)$ & $0(0)$ \\
HYB & $38(38)$ & $30(94)^{\star}$ & & $12(36)$ & $35(85)^{\star}$ \\
Mortality & $1(1)$ & $7(22)^{\star+}$ & & $0(0)$ & $0(0)$ \\
\hline
\end{tabular}

Patients in group $\mathrm{C}$ were subjected to open-heart surgery; patients in group $E$ were subjected to oesophagectomy. Values are expressed as number (percentage). ${ }^{*} P<0.05$, versus patients without infection; ${ }^{+} P<0.05$, versus patients without hyperbilirubinaemia (HYB).

and Miholic [10] suggests that postoperative hyperbilirubinaemia is mainly due to an increase in unconjugated bilirubin of haemolytic origin. These factors may influence the development of hyperbilirubinaemia soon after open-heart surgery with CPB. The rapid postoperative development of hyperbilirubinaemia in patients in the $\mathrm{E}$ group is clearly due to stress factors other than CPB.

Hyperbilirubinaemia after CPB has been considered to be due to an increase in bilirubin load that results from haemolysis, and researchers have been developing CPB tech-
Table 6

\section{Duration of ICU stay}

\begin{tabular}{llc}
\hline & C group & E group \\
\hline Total & $6.9 \pm 1.1$ & $8.5 \pm 1.0$ \\
non-HYB & $4.0 \pm 0.3$ & $5.8 \pm 0.4^{*}$ \\
HYB & $9.6 \pm 1.7^{\dagger}$ & $10.1 \pm 1.2^{\dagger}$ \\
\hline
\end{tabular}

Patients in group $\mathrm{C}$ were subjected to open-heart surgery; patients in group E were subjected to oesophagectomy. Both groups were divided into subgroups according to the existence of hyperbilirubinaemia (HYB). Data are expressed as mean \pm standard error. ${ }^{\star} P<0.05$, versus patients in the $\mathrm{C}$ group; ${ }^{\dagger} P<0.05$, versus patients without $\mathrm{HYB}$.

niques to reduce the bilirubin load. Unconjugated bilirubin was not the main factor in the hyperbilirubinaemia of the C group patients in the present study. On the other hand, the patients with postoperative hyperbilirubinaemia were also those who received larger volumes of transfused blood, so large loads of bilirubin are related to postoperative hyperbilirubinaemia. Fukusaki et al [11] reported that hypotension and haemodilution during surgery results in worse postoperative values for biological liver function tests and TB. Patients who receive large volumes of transfused blood may have episodes of hypotension and/or anaemia during surgery, and this may be a cause of postoperative hyperbilirubinaemia. Hebert et al [12] reported high mortality for critically ill patients who received large volumes of transfused blood; the present results concur with this finding. 
Finally, with regard to risk factors, Wang et al [2] reported that patients with high preoperative levels of TB were more likely to develop postoperative hyperbilirubinaemia. We also found that patients in the C group who developed postoperative hyperbilirubinaemia had higher levels of TB in blood samples taken before surgery.

In conclusion, after open-heart surgery and oesophagectomy, the levels of serum TB in about half of the patients in the present sample increased to hyperbilirubinaemic levels. The operative time correlated well with the occurrence of hyperbilirubinaemia. Infection significantly correlated with both mortality and TB levels after open-heart surgery; early diagnosis and control of infection is crucial to prevent worsening hyperbilirubinaemia and associated mortality.

\section{Acknowledgement}

We are grateful to Dr Fujino $Y$ for insightful comments regarding the manuscript.

\section{References}

1. Michalopoulos A, Alovizatos P, Geroulanos S: Hepatic dysfunction following cardiac surgery: Determinants and consequences. Hepato-Gastroenterology 1997, 44:779-783.

2. Wang $\mathrm{MJ}$, Chao $\mathrm{A}$, Huang $\mathrm{CH}$, et al: Hyperbilirubinemia after cardiac surgery. J Thorac Cardiovasc Surg 1994, 108:429-436.

3. Tujinaka T, Kido Y, Ogawa M, et al: Postoperative hyperbilirubinemia after resection of thoracic esophageal cancer. Am J Gastroenterol 1990, 85:1473-1479.

4. Tsutsui S, Moriguchi S, Morita M, et al: Multivariate analysis of postoperative complications after esophageal resection. Ann Thorac Surg 1992, 53:1052-1056.

5. Hawker F: Liver dysfucntion in critical illness. Anaesth Intens Care 1991, 19:165-181.

6. Brooks GS, Zimbler AG, Bodenheimer HC Jr, Burchard KW: Patterns of liver test abnormalities in patients with surgical sepsis. $A m$ Surg 1991, 57:656-662.

7. Ryan TA, Rady MY, Bashour CA, Leventhal M, Lytle B, Starr NJ: Predictors of outcome in cardiac surgical patients with prolonged intensive care stay. Chest 1997, 112:1035-1042.

8. Collins JD, Bassendine MF, Ferner R, et al: Incidence and prognostic importance of jaundice after cardiopulmonary bypass surgery. Lancet 1983, i:1119-1123.

9. Chu CM, Chang CH, Liaw YF, Shieh MJ: Jaundice after open heart surgery: a prospective study. Thorax 1984, 39:52-56.

10. Klepetko W, Miholic J: Correspondence regarding 'Jaundice after open heart surgery: a prospective study.' Thorax 1985, 40:80.

11. Fukusaki M, Maekawa T, Yamaguchi K, et al: Combined effects of prolonged postaglandin E1-induced hypotension and haemodilution on human hepatic function. Eur J Anaesthesio/ 1997, 14:157163.

12. Hebert PC, Wells G, Tweeddale M, et al: TRICC investigators and the Canadian Critical Care Trials Group: does transfusion practice affect mortality in critically ill patients? Am J Respir Crit Care Med 1997, 155:1619-1623.

Authors' affiliation: Intensive Care Unit, Osaka University Hospital, Suita, Japan

Correspondence: Masaji Nishimura, MD, Intensive Care Unit, Osaka University Hospital, 2-15 Yamadaoka, Suita 565-0871, Japan. Tel: +8166879 5811; fax: +8166879 5823; e-mail: masaji@hpicu.med.osaka-u.ac.jp 